\title{
Produção de textos narrativos em pares: reflexões sobre 0 processo de interação
}

Telma Ferraz Leal

Patrícia Santos da Luz

UniversidadeFederaldePernambuco

Correspondência:

Telma Ferraz Leal

Rua Má rio Pin to, 49 - Bul trins

53320-340 - Olin da - PE

e-mail: tfleal@terra.com.br
Resumo

0 artigo analisa o processo de interação entre pares em produção de textos narrativos. A escolha de tal tema está atrelada a uma concepção básica de que a elaboração textual é uma atividade cognitiva e social que impõe uma coordenação de ações e de decisões de diferentes tipos. São necessários conhecimentos quanto à situação de interação imediata, quanto às práticas culturais, quanto ao gênero textual e quanto aos aspectos lingüísticos formais. Dessa forma, defen de-se a idéia deque o trabalho em pares pode favorecer a tomada de consciência acerca das decisões a tomar, pois idéias conflitantes desautomatizam a ta refa da escri ta. Argu men ta- setam bém quea in tera ção pode levar as crianças a trocarem informações e a testá-las durante a geração do texto, assim como a partilhar estratégias para coordenar as ações.

Foram realizadas atividadesindividuaise em dupla de escritade notícias, cartas e contos em uma turma de 3 a série (ensino fundamental, escola municipal de Recife, 21 crianças, 8 e 13 anos de idade).

Os resultados mostram que os textos produzidos pelas duplas foram melhores que os textos individuais em composições do tipo assimétrico (fraco-médio) e simétrico (médio-médio), não sendo tal ef eito marcante em du plascompostasporcrian çasde níveis iniciais (fraco-fraco). As análises dos protocolos evidenciaram que em interação as crianças negociam informações e estratégias para elaboração textual e que apresentam diversos tipos de dinâmica de trabalho, podendo haver divisão clara de papéis ou nego ci ação permanen teem cada trecho do tex to produzido.

Palavras-chave

Produção de textos - Interação - Ensino fundamental. 


\section{The production of narrative texts in pairs: reflections on the interaction process}

Telma Ferraz Leal

Patrícia Santos da Luz

UniversidadeFederaldePernambuco

\section{Abstract}

The article analyzes the interaction process between pairs of pupils in the production of narrative texts. The choice of this issue is linked to the basic conception that the creation of texts is a cognitive and social activity that entails a coordination of actions and decisions of various types. Knowledge is necessary about the situation of immediate interaction, about the cultural practices, the text genre, and about the formal linguistic aspects. Thus, the article defends the idea that working in pairs can promote the awareness of decisions to be made, because conflicting ideas de-automate the task of writing. It also argues that the interaction can make children exchange information and test them during the production of the text, as well as to share strategies to coordinate actions.

Activities were carried out with a third-year class (Primary School in Recife, 21 children aged 8 to 13) involving individual as well as pair writing of news, letters and short stories.

The results show that the texts produced in pairs were better than individual texts for pairs of asymmetric (weak-average) and symmetric (average-average) arrangement; the same effect was not noticeable in pairs of (weak-weak) symmetric arrangement. Analyses of the protocols reveal that, when interacting, children negotiate information and strategies of text creation, and that they display various types of work dynamics that may include a clear division of tasks or a continuous negotiation in each part of the text created.

Keyw ords

Correspondence:

Tel ma Fer raz Leal

Creation of texts - Interaction - Primary education.

Rua Má rio Pin to, 49 - Bul trins

53320-340 - Olin da - PE

e-mail: tfleal@terra.com.br 
Por que é importante analisar o processo de interação durante a produção textual?

A escolha deste tema foi definida por causa da grande importância do trabalho com produção de textos nas séries iniciais, como vêm sugerindo as diversas propostas curriculares de redes estaduais e municipais, apresentadas des deo início da déca da de 1980. Optou-se por trabalhar com textos narrativos, pois esses circulam bastante entre as crianças da Educação Infantil e das séries iniciais sob forma de textos orais(histórias reais e fictícias) e sob for ma de textos escritos (leitura de histórias, notícias, cartas, etc.).

0 pressuposto básico que guia essa proposta é o de que a aprendizagem de produção de textos compreende o desenvolvimento da capacidadede coordenarconhecimentosdevários níveis e atividades também diversificadas que estão em jogo no trabalho de escrita. 0 escritor precisa usar informações acerca das normas de notação da escrita; atentar para as normas gramaticais de marcação de concordância gramatical; usar recursos coesivos e sinais de pontuação; organizar o texto em parágrafos; decidir acerca das estruturas das frases; selecionar vocábulos; utilizar conhecimentos acerca do tipo de texto a produzir, tais como organização, seqüência de idéias, estilo de enunciação; refletir acerca do conteúdo a ser veiculado, entre outras decisões necessárias. Dessa forma, defende-se a idéia de que o trabalho em pares pode favorecer a tomada de consciência acerca das decisões a tomar, pois idéias conflitantes desautomatizam a tarefa da escrita. Defende-se, também, que a interação pode levarascrian çasatro ca rem in for maçõese a testá-las durante a geração do texto, assim como a partilhar estratégias para coordenar as ações durante a atividade. Resta, portanto, investigar mais detalhadamente as formas como as crianças se organizam em tal tipo de atividade e se existem alguns tipos de pareamento (si- métricos ou assimétricos quanto ao nível das crianças em produção de textos) mais vantajosos que outros no processo de construção da competência textual.

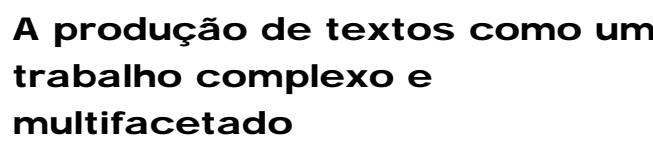

Muitos autores vêm pesquisando as competências de crianças em produção de textos. Góes e Smolka (1992), Abaurre (1992), Kato e Scavazza (1992), Santos (1997) salientam as diferenças de desempenho de crianças em produção de textos orais e escritos, mostrando as dificuldades que as crianças têm, muitas vezes, em adequar os textos às características próprias da escrita.

Em relação aos textos argumentativos, autores como Ostdam, Glopper e Eiting (1994) e Golder e Coirier $(1994,1996)$ mostram que crianças abaixo de 14 anos são pou co eficientes em produzir textos argumentativos escritos. Os autores apontam que as crianças não apresentam todos os elementos constituintes de um texto argumentativo (ponto de vista, justificativa, contra-argumentação e resposta). Golder e Coirier (1994) apresentamal gu mas hi pó tesesparataisresultados: crianças mais jo vens não têm ain da do mínio de processos cognitivos necessários à tarefa; ou as operações são dominadas separadamente, mas as crianças são incapazes de coordená-las para produção de um texto elaborado; ou as operações são dominadas, mas as crianças carecem de um modelo de comportamento argumentativo geral, particularmente a associação entre a meta e os constituintes do discurso.

Em relação aos textos narrativos, também foram realizados estudos que mostraram dificuldades estruturais. Rego (1986) e Brandão (1994), entre outros, discutiram o desempenho de crianças em escrita de histórias, mostrando que estas passam por um processo 
de construção dos esquemas textuais e que a história completa (situação inicial, desequilíbrio e desfecho) só é produzida após um certo tem po dein ter ven ção econ ta to com essegênero textual.

Outras dificuldades têm sido apontadas. Góes e Smolka (1992) descreveramdificuldades quanto ao uso dos pronomes em construções complexas de referên ciassu cessivas. Mu u itasvezes, não se sabe a que o "ele" se refere em meio a duas ou mais possibilidades. Piéraut-Le Bonniec e Valette (1991) e Kail e Weissenborn (1991), entre outros, verificaram dificuldades em utilizar conectivos lógicos.

É importante, no entanto, verificar que tais dificuldades são vistas, geralmente, como foco isolado e que a criança, ao produzir o texto, precisalidarcom to daselassimul taneamente. Em relação a esse processo, Vieira (1992) mostra, por exemplo, que o desempenho das crianças quanto ao uso de elipses é diferente nos diversos tipos textuais (narrativos, argumentativos e descritivos), ou seja,

odo mínio deumacatego riareferencialdepen de do domínio de um tipo de esquema. Para construir uma operação de nível mais baixo como a elip se, épreci so quea cri an ça do mi neuma ca tegoria de nível mais elevado, como o esquema textual.

Nessa mesma direção, Brandão (1994) aponta que as crianças que produzem as meIhores histórias, além de abarcarem todos os componentes básicos desse tipo textual, também apresentam maior elaboração na estruturação das sentenças.

A coordenação entre todas as ações (decidir conteúdo, estruturar e relacionar os períodos, organizar a seqüência, delimitar pará grafos, no taro tex to, en treou tras) ení veisde conhecimento (ortográficos, gramaticais, discursivos, textuais) deve ser guiada pelo sentido pretendido no texto e pelo efeito que se pretende provocar.
Leal e Guimarães (1999) atentam que

as decisões acima explicitadas são tomadas, muitas vezes, sem que 0 au tor per ce ba os di lemas, tal é sua familiaridade com o tipo de texto ou tal é a sua fal ta de cons ciên cia acer ca das múltiplas possibilidades. Além disso, não são decisões tomadas todas na fase preliminar de planejamento. Muitas dessas decisões, assim como a co or dena ção com a busca dos recur sos coesivos, são tomadas na própria atividade de gera ção do texto. Assim, mui tosau to res, como Rego (1988), Góes e Smolka (1992), Weisz (1992) e Kato (1995), advertem que a criança precisa desenvolver habilidades metacognitivas de planejamento, monitoração da atividade, revisão, avaliação do texto produzido. Durante toda a tarefa, a monitoração da ação possibilita retomadas e refacções. (p. 11)

A hipótese básica investigada nessetrabalho é que as dificuldades que as crianças encontram nas produções não decorrem simplesmente do desconhecimento de regrasgramati ca is ou da fal ta deidéi asso breas di versas partes que devem compor o texto. Na realidade, a conju gação dosváriosníveisdeco nhecimento e a coordenação das várias tarefas a desenvolver durante a escrita implicam um esforço permanente de concentração em fun ção do objetivo maior, que é o de dar unidade e comunicabilidade ao texto. Assim, torna-se necessário, a todo momento, planejar e executar tanto no plano geral (nível macro: decisões acerca do conteúdo e da estrutura geral do texto) quanto no plano das particularidades (nível micro: as diversas partes que 0 compõem).

Quando o professor entende essas dificuldades, ele passa a contribuir mais para que a criança consiga fazer distinção entre gerar o texto e pensar sobre ele, como bem salientam autores como Góes e Smolka (1992) e Cafiero (1996), entre outros. A coordenação entre 0 planejamento e a geração e as tomadas de 
decisões sobre a forma e o conteúdo são essenciais para a produção de qualquer tipo de texto e devem ser fei tas a partir da ima gem quese faz do leitor provável ou pretendido e da situação de interação que será mediada pelo texto. Logo, é necessário que se proporcione, na prática pedagógica, situaç̧ões reais de interação.

\section{A interação como elemento de reflexão}

A interação social vem sen do, des dea década de 1980, estudada e discutida enfaticamente por pesquisadores de diferentes áreas. É comumencontrarmos artigossalientan do aimportância da interação para construção do conhecimento. No entanto, ainda há muito a ser feito para elucidar, no nível microgenético, 0 papel da interação sobre a ação mental e sobre o desenvolvimento dos processos cognitivos, assim como para caracterizar com mais detaIhes os diferentes processos interacionais e os seus impactos sobre a atividade coletiva e individual.

Entre os profissionais da Educação, vigora a concepção de que a interação planejada é uma "estratégia privilegiada para promover e/ou aprimorar a construção de conhecimentos por parte dos alunos" (Davis, Silva e Espósito, 1989, p. 50). Entretanto, não há clareza, ainda, sobre quais processos cognitivos são ativados durante diferentes tipos de in terações. Porisso, as interações são vistas de modo genérico, sem que seja possível "elucidar quais delas são realmente úteis para a situação de sala de aula e quais delas cabe ao professor promover e/ou incentivar" (Davis, Silva e Espósito, 1989, p. 50). Segundo os autores citados, cabe ao professor/interventor criar condições para a colaboração, compreensão mútua e comunicação produtiva, além de discutir regras de interação (troca).

Em rela ção ao con tex to esco lar, Vygotsky (1984) alerta para a necessidade de se considerar o nível de desenvolvimento potencial dos alunos, ou seja, o quanto a criança é capaz de aprender sob a orientação de um adulto ou em interação com outra criança mais capaz. Esse desenvolvimento poten cial, quando confrontado com o desenvolvimento real (o que a criança é capaz de fazer sozinha), cria a Zona de Desenvolvimento Proximal, na qual as interações são mais ef etivas, fornecendo bases para novas aprendizagens.

Davis, Silva e Espósito (1989, p. 52) afirmam que

a interação com o outro - seja ele um adulto ou uma criança mais experiente - adquire, as sim, um caráterestrutu rante na construção do conhecimento na medida em que oferece, além da di men são afetiva, de sa fio eapo io para a atividade cognitiva. A interação social atua, dessaforma, so breaZonadeDesen vol vi mento Proximal, fazendo com que processos maturacio naisem an da men to venhama secom pletar, fornecen do no vas basesparano vasapren dizagens.

Tais colocações parecem destacar o papel da interação assimétrica (experiente $X$ inexperiente) sobre a construção do conhecimento. Pode-se perguntar, então, se as interações entre iguais(si métricas)não po deriam, também, serem propulsoras da construção do conhecimento. Tal questão necessariamente vem acompanhada de uma outra: qual seria o papel da in teração simétrica? Seosin divíduos possuem níveis próximos quanto ao conhecimento em questão, como poderiam impulsionar a construção do conhecimento? Há alguma outra característica nas situações além do fornecimento de informações que possibilitam a aprendizagem?

Para Moro (1991), a intervenção do adulto deve orientar as tarefas e intermediar tro casen treascrian ças, favo recen do o conflito cognitivo, maximizando adequadamente os conflitos e provocando soluções estruturantes. Nas relações criança- criança, a autora 
observa situações de: regulagem mútua; imitações; complementação; ações opostas de iniciativa; e divisão de tarefas. Portanto, tanto as interações criança- criança (simétricas) como as interações adulto-criança (assimétricas) são importantes para que ocorram progressos expressivos na construção cognitiva. M oro afirma ainda que é importante um primeiro momento individual do sujeito com a situação problema asolucionar, pois a ação individual tem sentido e se transforma se defrontada com ou trasações individuais.

A reflexão sobre o papel da interação em duplas sobre o desenvolvimento da capacidade de produção de textos é imprescindível, pois como sugere Perret-Clermont (1979), situações nas quais as crianças precisam coordenar entre si ações ou confrontar opiniões podem provocar modificações na estruturação cognitiva e resolução de problemas dos alu nos. Essa idéia é defendida por outros autores como Borba (1996) e Roazzi e Bryant (1999). Concebe-se, pois, que é possí vel que, em in tera ção, ascrianças passem a explicitar os conhecimentos e ap reen dam estra tégi as deco or dena ção en treas atividadesnecessáriasà produção de um texto.

Convém destacar que a própria atividade de produção textual, mesmo que realizada individualmente, está inserida numa situação de interação. Nesse caso, interação entre produtor e leitor do texto. Quando o texto está sendo produzido, é a imagem do interlocutor que orienta as decisões a tomar. Nesse trabalho, no entanto, o foco de atenção está voltado para a interação entre pares durante a geração do texto.

\section{Como analisar o processo de interaçã o?}

Pesquisas sobre interação têm sido conduzidas geralmente mediante dois procedimentos básicos: análise do desempenho de crianças individualmente e em grupo, em tarefas diversas; ou análise do discurso produzido na situa- ção de interação em foco. A primeira forma analisa os efeitos do processo interativo por meio da análise do produto dessa interação. Alguns estudos adotam métodos experimentais em que se manipulam as características das situações de interação. A segunda forma analisa o processo de interação por meio de instrumentos metodológicos de abordagens pragmáticas de análise do discurso.

A concepção de linguagem como processo de interação fornece suporte teórico para os procedimentosmeto dológicos em que ações verbais são tomadas como objeto de análise. Nessa perspectiva, a linguagem é tomada como um fenômeno situado e os protocolos verbais são manipulados através de análises microgenéticas.

Dentre os precursores dos modelos atuais de Análise do Discurso, pode-se citar Grice (1971), que enfatizou o papel dos interlocutores nas situações de uso da linguagem, apontando que os mesmos interagem mutuamente mediante um "contrato de cooperação". Busca-se, por meio desse modelo, perceber a formacomo osinterlo cu to resreconhecem as intenções comunicativas do outro.

A análise de tais intenções foi realizada mais sistematicamente por Austin (1962) e Searle (1969, 1975). Enfatizando o princípio intencional da fala, tal abordagem explorou as três dimen sõesbásicas dos enunciados: ato locucionário (conteúdo pro posici onal, o queé dito); ato ilocucionário (intenção subjacente ao conteúdo proposicional, força); ato perlocucionário (efeito perlocucionário sobre o interlocutor). Searle $(1969,1975)$ classificou os atos de fala segundo suas intenções. Dentre as contribuições da Teoria dos Atos de Fala, Blum-Kulka (1997) destaca a atenção dada a quatro fenômenos:

1 - expressões não servem apenas para expressar proposições mas também para executar ações lingüísticas em contexto;

2 - a linguagem provê a seu falante uma variedade de significados lingüísticos, variando 
em níveis de transparência ilocucionária e proposicional para performance em todos os atos de fala;

3 - a mesma expressão, dependendo do contexto, pode servir para exercer diferentes funções pragmáticas;

4 - atos de fala podem ser diferenciados pelos tipos de precondições contextuais necessárias para seu sucesso na performance. (p. 47)

Tais postulados forneceram contribuições relevantes para 0 incremento de modelos teóricos, dentro de uma perspectiva pragmática, que buscam realizar análise de discurso. Uma das abordagens teóricas de destaque, hoje, é a Análise da Conversação. Segundo Marcuschi (1991, p. 6), os objetivos gerais dos teóricos da Análise da Conversação são descrever as estruturas da conversação e seus mecanismos organizadores; especificar os conhecimentos lingüísticos, paralingüísticos e socioculturais que devem ser partilhados para que a interação seja bem-sucedida; analisar os processos cooperativos presentes na atividade conversacional. É considerando tais objetivos que teóricos como Orsolini e Pontecorvo (1992), Edwards (1997, 1998) e Pomerantz e Fehr (1997), entre outros, utilizam a Análise do Discurso como instrumento para compreender os processos in terativosem salade aula.

Dispondo de tais instrumentos metodológicos, optou-se por analisar o processo de produção textual em pares através dos produtos das interações (os textos individuais e em duplas) e da análise dos discursos produzidos em situação de produção.

\section{Como os dados foram coletados?}

Esse trabalho foi realizado com uma turma de 3 a série do primeiro grau de uma escola municipal de Recife, composta por 21 crianças, de ambos os sexos, com idade variando entre 8 e 13 anos de idade.

Foram realizadas atividades de escrita de notícias, cartas e contos. Para cada tipo de tex- to, foi realizada uma tarefa de escrita individual de um texto, a partir da qual as crianças eram classificadas em fracas, médias e fortes. Após a classificação, as crian çaseramagru padas em duplas (fraco/fraco; fraco/médio; fraco/forte; médio/médio; médio/forte; forte/ forte) para produção de outro texto (em dupla), seguindo as mesmas orientações da produção individual. Todos os encontros foram filmados e audiogravados e os textos recolhidos para análise.

Quais foram os efeitos da interação?

A primeira atividadefoi realizadaapartir de uma discussão acerca de uma notícia divulgada na tele vi são de quea mãe de um alu no de uma escola particular, em Belo Horizonte, foi presa por discriminação racial. A pesquisadora perguntou ao grupo classe se eles tinham visto no dia anterior, no J ornal Nacional, a notícia sobre a prisão de uma mulher por racismo. Algumas crianças disseram que sim. Após isso, ascrian çasfa la ram so brea no tícia, en quan to a pesquisadora fazia perguntas, pedindo mais detalhes, haven do, assim, uma discussão so bre o racismo, com tomadas de posição.

As informações discutidas sobre a notícia foram: data; local; descrição das pessoas envolvidas (descrição física, função na escola - professora, aluno, mãe do aluno, diretora, funcionário); narração dos fatos; detalhes (ofensas, testemunhas, situação atual na prisão, tipo de crime, pu ni ção prevista parao crime, fala da professora).

A partir dos resultados obtidos, as criançasfo ram classifica dasem trêsníveis, seguindo os critérios abaixo:

Fraco: textos que não apresentaram as características desse gênero e/ou apresentaram um baixíssimo teor de informatividade (apenas três informações dadas) ou não informavam sobre aspectos essenciais (motivo da prisão, por exemplo). 
Médio: textos narrativos, com boa estrutura seqüencial e com as informações essenciais (quatro a seis informações), mas sem exploração dos detalhes, quedariammaiscredi bilidade ao texto.

Forte: textos narrativos, com introdução, boa estrutura seqüencial, alto teor de informatividade (a partir de seis informações dadas) e presença de recursos lingüísticos próprios ao tipo de texto solicitado.

Foram analisados os textos individuais e os textos das duplas seguindo os mesmos critérios acima explicitados. A Tabela 1 (na página 36) mostra que, após a interação, houve uma melhora nos resultados das duplas do tipo fraco-médio e médio-médio, uma vez que os textos produzidos em dupla foram classificados em níveis superiores aos textos produzidos por cada criança individualmente. As duplas fraco-forte e médio-forte produziram textos que foram classificados como fortes, ou seja, no nível da criança que obteve melhor resultado individualmente (não havia uma categoria acima para serem observadas mudanças). As duplas fraco-fraco e forte-forte permaneceram no mesmo nível.

Logo, podemos dizer que a interação simétrica do tipo fraco-fraco não possibilitou melhoria no texto produzido, pois, juntas, as crianças não conseguiram modificar ou reorganizar as informações textuais. Não houve nenhuma dupla que apresentasse um texto, em dupla, inferior aos textos individuais.

Para a pro du ção dascartasfoirealiza daa leitura de uma história (Memórias de um rio) sobre a poluição de um rio causada por uma in dústria. Após isso, os alunos interpretaram a história e discutiram sobre o tema. A partirdesse trabalho, a pesquisadora propôs aos sujeitos que escrevessem uma carta para o dono da indústria, falando sobre o problema da poluição no rio e sugerindo soluções.

As crianças foram classificadas em três níveis, de acordo com a adequação do texto às características tipológicas, ou seja, obser- vou-se se os componentes próprios ao tipo solicitado estavam presentes. Os componentes analisados foram: contextualizadores (cabeçalho, com localização no tempo e espaço, identificação do destinatário e remetente), introdução (saudação e apresentação dos objetivos da correspondência), corpo (assunto, com clareza do objetivo da carta e argumentação), despedida (saudação). Dessa forma, os critérios foram:

Fraco: textos sem contextualizadores (ou apenas alguns contextualizadores), confuso (sem clareza dos objetivos da correspondência);

Médio: tex toscomclarezadosobjetivoseboa organização das idéias, mesmo que tenham falhas no uso dos recursos coesivos;

Forte: textoscomcontextualizadores, clareza dos objetivos e boa organização das informações e defesa de argumentos.

Em relação à produção das cartas, pode-se observar na Tabela 1 que, para todos os sujeitos, a interação foi bastante proveitosa, uma vez que nenhum texto em dupla foi inferior aos textos individuais. As duplas fraco-fraco, fraco-médio e médio-médio apresentaram textos melhores que os textos individuais. As duplas fraco-forte e médio-forte apresentaram textos no mesmo nível das crianças mais "competentes" e a dupla forte-forte permaneceu no mesmo nível (não havia outra classificação possível). É interessante observar que duplas simétricas (fraco-fraco; médio-médio) apresentaram textos melhor estruturados que os produzidos individualmente.

Para trabalhar com produção de histórias, foi realizada a leitura de outra história (Fantasmas chateados), que tinha como personagens dois fantasmas. Após a discussão sobre a história, retomando personagens, trama, episódios e desfecho, a pesquisadora propôs que escrevessem uma nova história com os mesmos personagens (os dois fantasmas), para que crianças de outra escola pudessem ter a oportunidade de ler. 
A história é um texto narrativo, literário, que apresenta em sua estrutura três momentos diferentes (situação inicial, desequilíbrio, desfecho), que são enriquecidos por descrições e narração de episódios que recheiam o enredo. Nesse tipo de texto, as crianças foram classificadas em três níveis, seguindo os critérios de classificação:

Fraco: textos classificados nos níveis de 1 a 3. No ní vel 1, o tex to não era nar ra ti vo; no ní vel 2, a criança introduzia personagem, mas não apresentava conflito; no nível 3, apresentava a introdução do personagem e delineava conflito sem desenvolvê-lo, sendo este texto uma reescrita.

Médio: textos que foram classificados nos níveis 3 ou 4. No nível 3, a criança introduzia 0 personagem e delineava o conflito, sem desenvolvê-lo, mas tendo que criar tal conflito sem reescrever do texto original. No nível 4, o texto apresentava personagem, conflito e desfecho sem "episódio" (só núcleo), sendo esse texto uma reescrita.

Forte: textos classificados no níveis 4 e 5 . No nível 4, introduzia personagem, conflito e desfecho sem "episódio" (só núcleo), criando novo conflito. No nível 5, introduzia personagem, conflito e desfecho, com acréscimo de elementos de recheio (episódios).

Pode-se observar na Tabela 1 que todos os textos produzidos em duplas foram classificados como fortes, com exceção da dupla formada por crianças fraco/fraco. Logo, é possível concluir que a interação entre pares auxiliou a produção textual, fazendo com que as crianças pudessem refletir sobre os objetivos para produ ção eso breosaspec tosestru tu raisdo tipo de texto solicitado. Mais uma vez a dupla fraco-fraco não apresentou progresso.

Em suma, pode-se observar que nos três tipos de texto houve uma melhora significativa quando eles foram produzidos em pares. É interessante retomar que tanto duplas assimétricas (fraco/médio) quanto simétricas (médio/médio) produziram textos melhores na situação de interação entre pares, com exceção dadu plafra co/fra co em no tí cia ehistó ria.

É imprescindível investigar mais detidamente as situações de interação do tipo fraco-fraco. Nesse pesquisa não houve efeito do processo interativo em produção de notíciase histó rias. Tal resul ta do podeser decorren tede que essas crianças estavam em um nível de desenvolvimento tão inicial nessa competência que não apresentarammelhora, mas é possível que em estudos de intervenção, com repetidas situações de interação em duplas, possa haver evolução também em interações desse tipo.

Quanto às duplas em que havia uma ou mais crianças fortes, tal análise precisa ainda ser aprofundada, pois uma das crianças já apresentava desempenho muito bom, podendo ser esta a responsável pelo bom trabalho da dupla. Tal questão será aprofundada num trabalho posterior.

É importanteressal tarqueacategorização ado ta da não esgo ta oscritéri osrelevan tes para cada um dos tipos textuais, mas foram considerados os mais essenciais para classificação dos textos ora produzidos, devendo-se considerar que eram crianças de $3^{\text {a }}$ série(escola pública) e que se os critérios fossem maisrígidos correríamos o risco de nivelar todos os textos, o que impossibilitaria as análises acercas das diferenças entre as situações em análise.

O que aconteceu durante a produção dos textos?

As análises dos protocolos de interação foram realizadas de duas maneiras. Inicialmente, buscou-se, por meio da leitura dos protocolos, identificar no texto produzido (produto) as formas de participação de cada criança, ou seja, quem estava notando (registrando) 0 texto, quem estava decidindo 0 conteúdo em cada trecho, quem estava decidindo sobre a estruturação dos períodos 
Tabela 1. Análise dos textos (individuais e em duplas)

\begin{tabular}{|c|c|c|c|c|c|c|c|c|c|}
\hline \multirow[b]{2}{*}{ Produções } & \multicolumn{3}{|c|}{ Notícia } & \multicolumn{3}{|c|}{ Carta } & \multicolumn{3}{|c|}{ Conto } \\
\hline & Fraco & Médio & Forte & Fraco & Médio & Forte & Fraco & Médio & Forte \\
\hline Sujeito 01 & $x$ & & & $x$ & & & $x$ & & \\
\hline Sujeito 02 & $x$ & & & $x$ & & & $x$ & & \\
\hline Interação 01 X 02 & $x$ & & & & $x$ & & $x$ & & \\
\hline Sujeito 03 & & $x$ & & & $x$ & & & $x$ & \\
\hline Sujeito 04 & & $x$ & & & $x$ & & & $x$ & \\
\hline Interação $03 \times 04$ & & & $x$ & & & $x$ & & & $x$ \\
\hline Sujeito 05 & & & $x$ & & & $x$ & & & $x$ \\
\hline Sujeito 06 & & & $x$ & & & $x$ & & & $x$ \\
\hline Interação $05 \times 06$ & & & $x$ & & & $x$ & & & $x$ \\
\hline Sujeito 07 & $x$ & & & $x$ & & & $x$ & & \\
\hline Sujeito 08 & & $x$ & & & $x$ & & & $x$ & \\
\hline Interação 07 X 08 & & & $x$ & & & $x$ & & & $x$ \\
\hline Sujeito 09 & $x$ & & & $x$ & & & $x$ & & \\
\hline Sujeito 10 & & & $x$ & & & $x$ & & & $x$ \\
\hline Interação 09 X 10 & & & $x$ & & & $x$ & & & $x$ \\
\hline Sujeito 11 & & $x$ & & & $x$ & & & $x$ & \\
\hline Sujeito 12 & & & $x$ & & & $x$ & & & $x$ \\
\hline Interação 11 X 12 & & & $x$ & & & $x$ & & & $x$ \\
\hline
\end{tabular}

(enunciação de cada trecho). Dessa forma, foram encontradas algumas passagens em que a criança que estava com o lápis enunciava e notava 0 trecho, algumas passagens em que uma crian ça no ta va o trecho ea ou traenun ci a va, algumas passagens em que uma criança decidia sobre o que seria escrito e a outra criança decidia sobre como seria dito (enunciação), algumas passagens em que a criança que estava com o lápis registrava trechos sem submeter à aprovação do par. Essas diferentes atuações das cri an ças em pa resfo ram destaca das no texto através das cores das fontes, que possibilitam uma melhor visualização dessa dinâmica.
Após essa análise, buscou-se apreender mais sobre as operações em ação durante a geração do texto. Os protocolos foram retomados e cada ato de fala foi classificado. Dessa forma, foram observados atos de fala com diferentes funções, tais como:

1 - enunciação do texto: a criança propõe a forma como o texto (trecho) deve ser registrado;

2 - proposta de conteúdo: a criança propõe 0 que será dito, mas não define a estrutura do período;

3 - aprovação de sugestão: a criança dá sinal de que concorda com a proposta do colega; 
4 - discordância quanto à sugestão apresentada;

5 - repetição como registro mnemônico: a criança repete o que foi dito para que o trecho enunciado não seja esquecido;

6 - repetição como auxílio para o registro: a criança repete o que foi dito vagarosamente para auxiliar a notação (foco de atenção em aspectos ortográficos);

7 - repetição para retomada do texto: a criança repete 0 que foi dito para dar prosseguimento ao período em andamento;

8 - leitura para retomada do texto: a criança lê o texto para retomar a seqüência e decidir sobre a continuação;

9 - leitura para revisão;

10 - solicitação de prosseguimento: a criança so li ci ta queo pardêprosseguimen to ao tex to;

11 - intervenções para organizar a dinâmica da atividade em dupla.

Os diferentes atos de fala podem ilustrar, de forma clara, a complexidade do processo de geração de um tex to eas di feren tesaçõesqueo produtor precisa coordenar. As crianças, em duplas, podem explicitar estratégias e informações. 0 fato de uma criança proceder à leitura do texto para retomar o que foi escrito pode auxiliar a outra criança a adotar tal tipo de estratégia quando ela for produzir o seu texto in dividualmente. Igualmente importantes são as estratégias de repetição, com diferentes funções (auxílio mnemônico, retomada do texto para continuidade, auxílio para registro) e leitura (para retomada do texto e para revisão do que já está escrito).

Para ilustrar a dinamicidade das ações em jogo, foram selecionados dois protocolos que exemplificam alguns fenômenos que podem evidenciar a complexidade dos processos durante a geração de um texto. 0 primeiro protocolo constou de uma situação de produção de carta. Os textos produzidos individualmente pelas crianças envolvidas ( $\mathrm{N}$ e J) foram classificados como médios. $\mathrm{N}$ não colocou os contextualizadores da carta, produziu um texto curto e confuso, com muitas violações ortográficas. J utilizou os contextualizadores, mas fora do formato padrão. J foi melhor que $\mathrm{N}$ em ortografia e fez um texto mais longo porque enumerou os rios que não deveriam ser poluídos, mas não apresentou solução para o problema.

\section{deretorpor que quando você \\ fei se fabreca você não \\ boto um fico poreso \\ você acho que e traze \\ nata coze boa e você deretor \\ você a cabo a foreta.}

(Texto individual de $\mathrm{N}$ )

você dono da fabrica não queria que todo mundo fose joga lixo na sua casa não emtão porque você joga lixo da cua fabrica no Rio Capibaribe nas não e so por voce e para todos quetem fa brica atéos pi tal tudo naseas peso as não deveria joga lixo no Rio Cabibaribe e otros até 0 de paris da xina e da africa e da austral ha enu sul em pau lo nor te eo São pa u lo Rio deja nei ro Rio eti ju ca Rio ama zo nas eo Rio de camaraca o Rio da brazilite

Recife. 03 de junho de 1998 Ass. J ...

(Texto individual de J)

0 texto produzido em dupla, como pode ser visto abaixo, foi mais bem estruturado, com utilização dos contextualizadores, apresentação clara dos objetivos e desenvolvimento coerente da mensagem.

Recife, 20 de agosto de 1998

Para: Direto da Fabrica

Por favo dona da Fábrica mande faze outra Fabrica em outro lugar sinão vai acaba com a natureza sinão bota um fiutro para não acaba 
com a natureza é está poluido o mar e o ar Assinado: Nelson é J uliana

\section{( $X X$ - texto enunciado por $N$ ) \\ (XX - texto enunciado por J)}

Para analisarmelhoraorganização du rante a geração do texto, optou-se por demarcar quem estava enunciando cada parte da carta. Como pode ser observado, N (em itálico) foi respon sá vel pela enun ci a ção dequa se to do o tex to. Por meio da análise do diálogo, pode-se perceber que houve, nesse caso, uma distribuição de tarefas. Enquanto J (em negrito), que segurava o lápis, preocupava-se prioritariamente em notar o texto, N preocupava-se em enunciar.

Pode-se perceber, no diálogo, nas páginas 39 e 40, que J não teve um papel muito importante quanto às decisões sobre o conteúdo do texto, mas serviu como reguladora do texto de Nel son, além deter ati va do nele a necessi dade de colocar os contextualizadores. 0 fato de o lápis ter ficado com J fez com que $N$ pudesse pensar mais sobre a estrutura textual e enunciar um texto mais coeso. A leitura do texto individual de $\mathrm{N}$ pode levar a uma avaliação equivocada quanto à competência que o aluno tem em produzir um texto do tipo solicitado. Como foi dito anteriormente, o textoindividual de $\mathrm{N}$ não tinha os contextualizadores; $\mathrm{N}$ não apresentou com clareza os objetivos da correspondência e não conseguiu organizar as informações de forma coesa e clara. As dificuldades do aluno em ortografia podem tê-lo levado a in vestir mais nessa di men são, fa zen do com que ele não conseguisse coordenar as ações necessárias para gerar o texto. Muito investimento em ortografia era necessário, fazendo com que a enunciação ficasse em um plano inferior. J, por outro lado, tinha mais facilidade em registrar o texto, mas não planejou bem os conteúdos a veicular, tendo produzido um texto repetitivo. No texto em dupla, N pôde funcionar como modelo para J quanto ao processo de geração e organização das idéias e acerca das con - venções de uso dos contextualizadores. J , por outro lado, possibilitou que $\mathrm{N}$ exercessetal atividade por li berá-lo da ta refa deno taro tex to.

Diferentemente da dupla acima, W e A adotaram uma dinâmica em que não houve uma divisão tão clara de tarefas. Embora nos textos individuais (abaixo), as crianças tenham produzido notícias classificadas como médi as, quan do pro du zi ram em du pla, o tex to melhorou em qualidade, tendo sido avaliado com bom.

JONAL DO COMECIO

Recife, 20 de outubro de 1998

Titulo

A MÃE DO MENINO VIO APROFESORA FALANO DO MENINO QUE ELE CHEGAVA MUITO TATE NA ESCOLA PATICOLA EM BEROLISONTE A MÃE DO MENINO QUE CICHAMAVADENIS A MEA DE DENIFOI PRESA PORQE CHIGO A PROFESORA DE SENO QUE ELA É NEGRA E A MÃE DE DENI FOI PRESA ELA VAI SE APANHA DA PELO OS PULICIAL. ELA VAI SE CASTIGADA ASS: W...

(Texto individual de W)

\section{FOLHA DE PERNAMBUCO?}

$\mathrm{x}$

Um menino chegou atrazado na escola a pro fessora ficou recramando com ele e a mãe dele ouviu tudo e dissi com a professora e no era para você ser professora não era para você ser uma babar era bom que o carro batesse em você a deretora e as mãe dois outro meninos ficaram vendo e a professora chamou a polícia e a mãe do menino ficou chorando falando no nicrofone e a polícia levou a mãe do menino preza e ela sor sera solta ser ela passado juga men to ser ela não pas sar ela sera preza de 1 até 3 ano isso foi lar inberolizonde?

QUEM ESCREVEU FOI

A...?

(Texto individual de A) 
Protocolo de interação entre $\mathrm{N}$ x J em produção de carta

\begin{tabular}{|c|c|}
\hline Diálogo & Análise dos atos de fala \\
\hline \multicolumn{2}{|l|}{ (...) } \\
\hline N - Diz. & N solicita que J inicie o texto. \\
\hline J - Diz tu também... Por favor, dona da... & $\begin{array}{l}\text { J solicita que o colega o faça, mas logo após começa a } \\
\text { enunciar e registrar o texto. }\end{array}$ \\
\hline N - Fábrica, mande fazer essa fábrica em outro lugar. & $\mathrm{N}$ assume o turno, continuando a enunciação. \\
\hline $\begin{array}{l}\text { J - Essa fábrica... Mande fazer essa fábrica em outro } \\
\text { lugar. }\end{array}$ & $\begin{array}{l}\text { J repete o texto, registrando. A repetição parece ter a } \\
\text { função de auxílio mnemônico (para não esquecer o que } \\
\text { foi enunciado) e auxílio para o registro (momento em } \\
\text { que a menina preocupa-se com as questões notacionais } \\
\text { (registro do texto) }\end{array}$ \\
\hline N - Aí tu bota... senão... & $\mathrm{N}$ continua a enunciar \\
\hline J - Senão... & J repete para fazer o registro \\
\hline N - Senão vai acabar com a natureza. & N continua a enunciar \\
\hline J - Senão vai acabar com a natureza. & J repete \\
\hline $\begin{array}{l}\text { N - Aí tu bota... Senão bota... botar um filtro para não } \\
\text { acabar com a natureza e está poluindo } 0 \text { mar e } 0 \text { ar. } \\
\text { Pronto. }\end{array}$ & $\begin{array}{l}\mathrm{N} \text { continua a enunciar o texto e sinaliza que a tarefa } \\
\text { acabou. }\end{array}$ \\
\hline J - Pronto & J concorda com o colega \\
\hline \multicolumn{2}{|l|}{ (...) } \\
\hline $\begin{array}{l}\text { P - Pronto? Os dois concordam que acabou? Não está } \\
\text { faltando mais nada? }\end{array}$ & P procura confirmação sobre o término da atividade. \\
\hline \multicolumn{2}{|l|}{ N e J - Não } \\
\hline \multicolumn{2}{|l|}{ P - E agora? } \\
\hline J - É botar remetente para o cara que mandou. & $\begin{array}{l}\text { J lembra que é necessário colocar o nome do remetente } \\
\text { (contextualizador) }\end{array}$ \\
\hline \multicolumn{2}{|l|}{ P - É isso? } \\
\hline N - É pra fazer uma carta, é? Ou é uma carta normal? & $\begin{array}{l}\text { N procura informações sobre o tipo de texto que estão } \\
\text { produzindo (parece que não havia percebido que deveria } \\
\text { escrever uma carta "de verdade") }\end{array}$ \\
\hline \multicolumn{2}{|l|}{ P - É uma carta normal. } \\
\hline J - Bota remetente. & J repete que é necessário colocar o remetente \\
\hline \multicolumn{2}{|l|}{$P$ - É? } \\
\hline $\begin{array}{l}\text { N - Eita! E se fosse para fazer o nome, aí a gente ti- } \\
\text { nha que botar Recife, o lugar onde a gente tava. A } \\
\text { gente se esqueceu de tudinho, não foi não? }\end{array}$ & $\begin{array}{l}\text { A intervenção de J ativa os conhecimentos prévios de } \mathrm{N} \\
\text { sobre os contextualizadores do texto }\end{array}$ \\
\hline \multicolumn{2}{|l|}{ P - 0 que foi Nelson, que esqueceu? } \\
\hline N - De botar Recife, qual dia foi... A gente esqueceu. & \\
\hline
\end{tabular}


Protocolo de interação entre $\mathrm{N} \mathrm{x} \mathrm{J} \mathrm{em} \mathrm{produção} \mathrm{de} \mathrm{carta} \mathrm{(cont.)}$

J - Mas, bota embaixo.

N - Não!

$P$ - Tem jeito ainda de fazer isso?

$\mathrm{N}$ - Ter, tem. Só que aqui é muito grosso. Só se fazer uma lista bem grande aqui, olha!

J - Bota uma régua.
J propõe que os contextualizadores sejam colocados em locais não convencionais (da mesma forma que fez no texto individual)

$\mathrm{N}$ não aceita

$\mathrm{N}$ procura uma solução para o problema, aproveitando 0 espaço superior do papel

J solicita que isso seja feito de forma organizada (com régua)

P - Combina com ela.

$\mathrm{N}$ - Com quem?

P - Com J uliana.

N - Heim? Vai fazer? Pronto, agora... bota Recife, a

data, onde a gente tá, olha a vírgula aqui... de 1998.

Pronto. Aí bota o nome da pessoa. Como é o nome da

$\mathrm{N}$ orienta J sobre a maneira como os contextualizadores pessoa?

devem ser colocados.

$P$ - Não é pro diretor, né? Que a gente tá escrevendo?

$\mathrm{N}$ - É, aí bota o nome diretor. $\quad$ N enuncia 0 texto

$P$ - Eu não sei o nome dele, vocês também não sa-

bem. Chama ele de diretor.

$\mathrm{N}$ - Aí bota o nome diretor. Aqui embaixo.

J - Diretor da fábrica. J complementa

$\mathrm{N}$ - Aqui embaixo tu bota: assinado Nelson e J uliana, vai? Assinado é com dois "s", é? Vai, dita seu nome... Nelson e J uliana, bota um "i", não?

$\mathrm{N}$ auxilia J quanto ao registro, explicitando dúvidas quanto à ortografia.

J - Um "e"? J responde sobre a dúvida colocada.

$\mathrm{N}$ - É um "e" mesmo?

J - Pronto.

W individualmente apresentou um texto com muitos problemas ortográficos e organizacionais, sem utilizar uma linguagem apropriada ao tipo de texto solicitado e baixo teor de informatividade. Os detalhes que servem para dar credibilidade ao texto jornalístico não foram explicitados. A, por outro lado, mostrou ser meIhor em ortografia do que $W$, mas o texto individual estava mais confuso. Nenhuma das duas crianças demonstrou facilidade em organizar as informações no texto. É comum, nesse tipo de texto, apresentar inicialmente as informações mais gerais e depois os detalhes que caracterizam a cena ou o fenômeno que está sendo descrito. A, em seu texto individual, acrescentou informações não verídicas ao texto, fato que demarca um descomprometimento com a veridicidade própria do texto jornalístico. 
0 texto em dupla, como pode ser visto abaixo, apresentou uma melhor organização das idéias, com uma maior quantidade de informações reais e ausência de informações inventadas.

UM ALUNO J EGOU ATRASADO NA ISCOLA PATICULA

EN BEROULISOTE A PROFESSORA FICOU RECRAMANO COM ALUNO A MÃE DO ALUNO ESCUTO E COMEÇOU A CHIGA A PROFESSORA DESENO QUE ELA ERA NEGRA E DISE QUANDO VISE ELA NA RUA IA PASA PO PO SIMA DELA E A PROFESSORA IAMO A POLICIA A POLICIA LEVOU A MÃE DO ALUNO PRESA E DESE QUE NO PODE PAGA FIANÇA ELA PODE SAI NO JUGAMETO.

\section{XX - TRECHO ENUNCIADO POR W \\ $X X$ - TRECHO ENUNCIADO POR A \\ $\underline{\underline{X X} \text { - TRECHO ENUNCIADO POR A E W }}$}

\section{CONCOMITANTEMENTE}

XX - TRECHO REGISTRADO POR W SEM SUBMETER À APRECIAÇÃO DE A

$X X$ - TRECHO ENUNCIADO POR A E MODIFICADO POR W, SEM CONSULTA AO PAR

XX - TRECHO ENUNCIADO POR W E MODIFICADO POR A

Através da visualização do texto é possí vel perceberquenão hou ve, nessecaso, uma divisão rígida de papéis, pois, embora $W$ tenha ficado com a tarefa de notar o texto, a enunciação foi realizada pelas duas crianças. Por outro lado, pode-se verificar que $\mathrm{W}$ tinha mais poder sobre o texto, pois ele é quem fazia modificações nos trechos enunciados por A sem realizar consulta prévia, assim como registrou a palavra "particular" em silêncio. Tal característica fica evidente na análise do protocolo (abaixo).

Protocolo de interação entre W x A em produção de notícia

\begin{tabular}{|c|c|}
\hline \multicolumn{2}{|l|}{$(\ldots)$} \\
\hline W - Eu fico com o lápis & $\begin{array}{l}\text { W informa sobre uma decisão sobre a dinâmica de traba- } \\
\text { lho. }\end{array}$ \\
\hline \multicolumn{2}{|l|}{$(\ldots)$} \\
\hline W - Diz aí. & W solicita que $A$ enuncie 0 texto. \\
\hline A - No dia 20 de outubro de $1998 \ldots$ & A enuncia 0 texto. \\
\hline \multicolumn{2}{|l|}{ W - Diz alto menina. } \\
\hline \multicolumn{2}{|l|}{$\begin{array}{l}\text { P - É. Tem que falar alto, você vai querer ouvir de- } \\
\text { pois na voz... }\end{array}$} \\
\hline A - Um aluno chegou atrasado na escola. & A enuncia 0 texto. \\
\hline W - Fala alto menina. Em Belo Horizonte, não foi? & W confirma o trecho enunciado. \\
\hline A - Em Belo Horizonte. & A confirma o trecho enunciado. \\
\hline $\begin{array}{l}\text { W - A mãe do aluno escutou e começou a xingar a } \\
\text { professora. }\end{array}$ & W enuncia o trecho. \\
\hline A - Não. A professora reclamou com o aluno. & $\begin{array}{l}\text { A rejeita a proposta do colega e propõe outra ordem a } \\
\text { ser registrada. }\end{array}$ \\
\hline$(\ldots)$ & \\
\hline
\end{tabular}


Protocolo de interação entre W $\times$ A em produção de notícia (cont.)

\begin{tabular}{|c|c|}
\hline $\begin{array}{l}\text { W - Reclamando. A mãe do aluno escutou e come- } \\
\text { çou a xingar a professoa. }\end{array}$ & $\begin{array}{l}\text { W modifica o trecho enunciado mantendo o conteúdo e } \\
\text { prossegue retomando o trecho rejeitado por } A \text {. }\end{array}$ \\
\hline A - Escutou... & $\begin{array}{l}\text { A aceita o trecho enunciado na nova ordem em que foi } \\
\text { posta e auxilia o colega repetindo o trecho que ele estava } \\
\text { registrando. }\end{array}$ \\
\hline$W-E$ & W repete enquanto registra. \\
\hline A - A professora, dizendo que ela era negra. & $\begin{array}{l}\text { A repete um pedaço do trecho, auxiliando W a notar (a } \\
\text { professora) e dá continuidade, enunciando o restante do } \\
\text { período. }\end{array}$ \\
\hline \multicolumn{2}{|l|}{ W - Fala alto menina. } \\
\hline $\begin{array}{l}\text { A - Dizendo que quando ela fosse atravessar uma } \\
\text { rua... }\end{array}$ & A enuncia novo período. \\
\hline $\begin{array}{l}\text { W - E disse que quando visse ela na rua, ia passar } \\
\text { por cima dela. Acabou... a história. }\end{array}$ & $\begin{array}{l}\text { W modifica o trecho enunciado e registra-o no papel. } \\
\text { W informa o término da atividade. }\end{array}$ \\
\hline A - Não, ainda tem mais. & $\begin{array}{l}\text { A não aceita a sugestão, defendendo que ainda é neces- } \\
\text { sário completar a notícia. }\end{array}$ \\
\hline W - Então diz. & $\begin{array}{l}\text { W solicita que ela assuma a enunciação do restante do } \\
\text { texto. }\end{array}$ \\
\hline \multicolumn{2}{|l|}{ (...) } \\
\hline \multicolumn{2}{|l|}{$\begin{array}{l}\text { P - Peraí, ele tá achando que acabou. Ela que não, } \\
\text { não é isso? Então faz o seguinte: lê a história do co- } \\
\text { meço e vê se acabou mesmo. Vê se tá faltando, tá } \\
\text { certo? }\end{array}$} \\
\hline A - Bota aí... & A pensa sobre 0 que irá propor. \\
\hline $\begin{array}{l}\text { W - (lê o texto) Um aluno chegou atrasado em uma } \\
\text { escola em Belo Horizonte. A professora ficou recla- } \\
\text { mando com o aluno. A mãe do aluno escutou e co- } \\
\text { meçou a xingar a professora... }\end{array}$ & W lê o texto para retomar e dar continuidade. \\
\hline $\begin{array}{l}\text { W e A - ... dizendo que ela era negra e disse quando } \\
\text { visse ela na rua ira passar por cima dela. }\end{array}$ & $\begin{array}{l}\text { W e A continuam a leitura do texto para dar prossegui- } \\
\text { mento ao mesmo. }\end{array}$ \\
\hline W e A - E a professora chamou a polícia. & W e A enunciam novo trecho concomitantemente. \\
\hline A - Polícia e disse... & A tenta continuar 0 texto. \\
\hline W - Polícia e disse... & W tenta continuar o texto. \\
\hline A - ... levou a... um... mãe do aluno presa. & A enuncia novo período. \\
\hline W - Presa. Acabou, fim. & $\begin{array}{l}\text { W repete para notar o fim do período e sugere que a ati- } \\
\text { vidade seja concluída. }\end{array}$ \\
\hline A - E disse que ela não pode... & A ignora a sugestão e continua a enunciar. \\
\hline
\end{tabular}


W - E disse que ela não pode... não pode pagar imposto.

A - ... pagar fiança.

W - Ela não pode sair no julgamento. Acabou. Acabou.
W continua a enunciar o período de onde A parou.

A modifica o trecho sugerido (imposto / fiança)

W enuncia fim do texto e informa que a atividade chegou ao fim.
Apesar de W ter enunciado a maior parte do texto, fica evidenteque $A$ tem um papel decisivo na organização das informações, poisin terferia, quando necessário, para que W não colocasse os dados de forma desordenada (por exemplo, no início, não deixou que ele escrevesse que "a mãe do aluno escutou" antes de dizer que "a professora reclamou com o aluno"). A também fez intervenções relevantes para que uma maior quantidade de informações fosse registrada, pois não deixou que seu colega finalizasse a tarefa na quarta linha.

É interessante perceber que no texto individual de $W$, ele teve dificuldades em fazer a introdução e, no texto em dupla, foi A quem iniciou a enunciação, embora eles tenham perdido o começo do trecho ditado, quando $\mathrm{A}$ propunha que fosse colocada a data em que 0 episódio aconteceu (no dia 20 de outubro de 1998).

Apesar de $W$ ter mostrado dificuldades em conectar as idéias no seu texto individual, ele pôde, com o auxílio de A, pen sarem pequenas passagens do texto, retomando o que já tinha sido escrito. Esse tipo de composição, como pode ser observado no texto, é muito rica, pro pi cian do quecada crian ça apreen daestratégias e informações do colega.

\section{Conclusão}

Verificamos que, em duplas, as crianças, quando negociavam as diferentes concepções que tinham sobre uma determinada questão, geralmente conseguiam melhores resultados do que quando estavam produzindosozinhas.

Percebemos, também, que, ao ficarem em tal situação, ossu jei tossevi ram instadosa tomar decisões não mais sozinhos, e, por isso, obrigados a explicitar o que estavam querendo fazer, o que sabiam fazer, e para isso tinham que se fazer entender pelo outro, validar o que queriam dizer, confrontar suas idéias, trocá-las. Enfim, deci dircomo escrever o texto. Depois de passarem por uma certa reflexão sobre sua estrutura, modificavam ou não o que queriam escrever, resolvendo, portanto, entre o que ele "achava" que devia colocar e o que o outro "achava", sendo tal decisão tomada a partir da explicitação mais con vin cen te, ou, ain da, poraquelesu jei to que fosse mais autoritário.

Constatamos que, apesar de as produções dos sujeitos em interação terem apresentado melhores resultados, o simples fato de colocar tais sujeitos nessa situação nem sempre é um fator determinante para se obter um melhor desempenho, como pôde ser observado nos textos produzidos pelas duplas fraco-fraco em notícia e conto. Além disso, foi observado que algumas crianças explicitaram boas sugestões para a escrita dos textos trabalhados, mas foram vencidas pelas argumentações dos parceiros, talvez mais persuasivos.

A maioria das duplas simétricas (fraco-fraco, em carta; e médio-médio, em carta, conto e notícia) apresentou melhores resulta- 
dos em interação. Acreditamos que esses sujeitos, quando foram colocados nesse tipo de situação, puderam refletir sobre suas respostas iniciais e as respostas diferentes das suas e, assim, reelaborar seus conhecimentos.

Quanto às duplas assimétricas (fraco-médio em conto, carta e notícia), também apresentaram melhores resultados, fazendo-nos acreditar que houve real men teumaboa melhora após as situações de interação e que estas, portanto, podem facilitar a aprendizagem das crianças.

As duplas que tinham uma ou duas crianças fortes (fraco-forte, médio-forte e forte-forte) permaneceram fortes quando produziram em díade. Tal tipo de composição será posteriormente explorada mais detidamente, pois poderá fornecer informações valiosas sobre as estratégias já adquiridas por crianças nesse nível de escolaridade.

As situações de interação fornecem informações im portantesparao desem penho de um melhor trabalho em sala de aula. Os sujeitos envolvidos percebem que existem respostas diferentes das suas e que a partir dessas diferenças podem trocar idéias e refazer tais respostas. Nós, educadores, sabemos que os alunos podem, ainda, melhorá-las, reelaborá-las, após as explicitações, enquanto trocam esses conhecimentos, podendo, dessa forma, favorecer suas aprendizagens. Os trabalhos em duplas são, portanto, poderosos recursosno pro ces so de construção do co nhecimento das crianças em sala de aula.

\section{Referências bibliográficas}

ABAURRE, M.B.M. 0 que revelam os textos espontâneos sobre a representação que faz a criança do objeto escrito? In: KATO, M. A concepção de escrita pela criança. 2 ed. Campinas: Pontes, 1992.

AUSTIN, J. How to do things with words. Oxford University Press, 1962.

BLUM-KULKA, S. Discourse Pragmatics. In: VAN DIJ K, T. A. Discourse as Social Interaction. London: SAGE Publications, 1997.

BORBA, E.S.R. A resolução de problemas aditivos com inteiros relativos: conhecimentos anteriores e a interação de pares. Recife; 1996. Projeto de Pesquisa - UFPE, 1996.

BRANDÃO, A.C.P. A. Produção e compreensão de histórias por crianças. Recife; 1994. Dissertação (Mestrado) - UFPE.

CAFIERO, D. A produção da informatividade na escrita. Boletim da Associação Brasileira de Lingüística, 19, p. 153-162.1996.

DAVIS, C., SILVA, M \& ESPÓSITO, Y. Papel e valor das interações sociais na sala de aula. Cadernos de pesquisa. 71, 1989. p. 49-54.

EDWARDS, D. Discourse and cognition. London: Sape, 1997.

EDWARDS, D. Em direção a uma psicologia do discurso em sala de aula. In: COLL, C. \& EDWARDS, D. Ensino, aprendizagem e discurso em sala de aula: aproximações do estudo do discurso educacional. Porto Alegre: Artes Médicas, 1998.

GÓES, M.C.R. e SMOLKA, A.L.B. A criança e a linguagem escrita: considerações sobre produção de textos. In: ALENCAR, E.S. Novas contribuições da Psicologia aos processos de ensino e aprendizagem. São Paulo: Cortez, 1992.

GOLDER, C. \& COIRIER, P. Argumentative text writing: developmental trends. Discourse Processes, 18, 1994. 187-219.

GOLDER, C. \& COIRIER, P. The production and recognition of typological argumentative text markers. Argumentation, 10, 1996. 271-282.

GRICE, H.P. Meaning. In: D. STEINBERG and L. JAKOBOVITS (eds.). Semantics: na interdisciplinary reader in Philosophy. Cambridge: Cambridge University Press, 1971. 
KAIL, M. \& WEISSENBORN, J . Conjunctions: developmental issues. In: G. PIÉRAUT - LE BONNIEC \& M. DOLITSKY (eds.). Language bases... discourse bases. Amsterdam: J ohn Benjamins Publishing Company, 1991.

KATO, M. A. e SCAVAZZA, B. A produção de estruturas coordenadas reduzidas por crianças na linguagem oral e escrita. In: KATO, M.A. A concepção de escrita pela criança. 2 ed. Campinas: Pontes, 1992.

KATO, M. A. No mundo da escrita: uma perspectiva psicolingüística. 5 ed. São Paulo: Ática, 1995.

LEAL, T.F. e GUIMARÃES, G.L. Como as professoras avaliam os textos narrativos das crianças? $22^{2}$ REUNIÃO ANUAL DA ANPED. Anais (CD room). Caxambu: ANPED, 1999.

MARCUSCHI, L. A. Análise da conversação. São Paulo: Ática, 1991.

MORO, M. Crianças com crianças, aprendendo: interação social e construção cognitiva. Cadernos de pesquisa, 79, 1991. p. 31-43.

ORSOLINI, M. \& PONTECORVO, C. Children's talk in classroom discussions. Cognition and instruction, 9 (2), p. 113-136, 1992.

OSTDAM, R.; GLOPPER, K. \& EITING, M.H. Argumentation in written discourse: secondary school students' writing problems. In: F.H. VAN EEMEREN \& R. GROOTENDORST (eds). Studies in Pragma-dialectcs. Amsterdam: Sec. Sat, 1994.

PIÉRAUT - LE BONNIEC, G. \& VALETTE, M. The development as argumentative discourse. In: G. PIÉRAUT - LE BONNIEC \& M. DOLITSKY (eds). Language bases and discourse base. Amsterdam: J ohn Benjamins Publishing Company, 1991.

PERRET-CLERMONT, A. N. A construção da inteligência pela interação social . Lisboa: Sociocultural, Divulgação Cultural, 1979.

POMERANTZ, A. \& FEHR, B.J. Conversation analysis: na approach to the study of social action as sense making practices. In: VAN DIJ K, T. A. Discourse as social interaction. Discourse studies: a multidisciplinary introduction. vol. 2. London: Sape, 1997.

REGO, L. L. B. A escrita de estórias por crianças: As implicações pedagógicas do uso de um Registro Lingüístico. D.E.L.T.A., 2(2), p. 165-180, 1986. Literatura infantil: uma nova perspectiva da alfabetização na pré-escola. São Paulo: FTD, 1988.

ROAZZI, A e BRYANT, P.E. Interação social e inferência lógica. Recife; 1999. Mímeo (artigo ainda não publicado) - UFPE.

SANTOS, S.L. 0 desenvolvimento da escrita argumentativa. Arquivos Brasileiros de Psicologia, vol. 49, n 3, 1997. 23-42.

SEARLE, J. Speech acts. Cambridge: Cambridge University Press, 1969.

SEARLE, J. Indirect speech acts. In P. COLE AND J. MORGAN (Eds.). Syntax and Semantics 3: Speech acts. New York: Academic Press, 1975.

VIEIRA, M. A. C. 0 desenvolvimento da elipse em textos narrativos, descritivos e argumentativos. In: M. A. KATO (Org.). A concepção da escrita pela criança. $2^{\text {a }}$ ed. Campinas: Pontes, 1992.

VYGOTSKY, L.S. Interação entre aprendizado e desenvolvimento. In: M. COLE, V.J .STEINER, S.SCRIBNER E E. SOUBERMAN (Org.). A formação social da mente. São Paulo: Martins Fontes, 1984.

WEISZ, T. Por trás das letras. São Paulo: FDE, 1992.

Recebido em 27.06.01

Aprovado em 04.09.01

Telma Ferraz Leal é mestre em Psicologia Cognitiva, doutoranda em Psicologia Cognitiva e atualmente professora da Universidade Federal de Pernambuco (DMTE - Centro de Educação).

Patrícia Santos da Luz é professora da Escola Arco Íris ( $2^{\text {a }}$ série), Graduada em Pedagogia e bolsista do Programa de Iniciação à Docência da UFPE. 